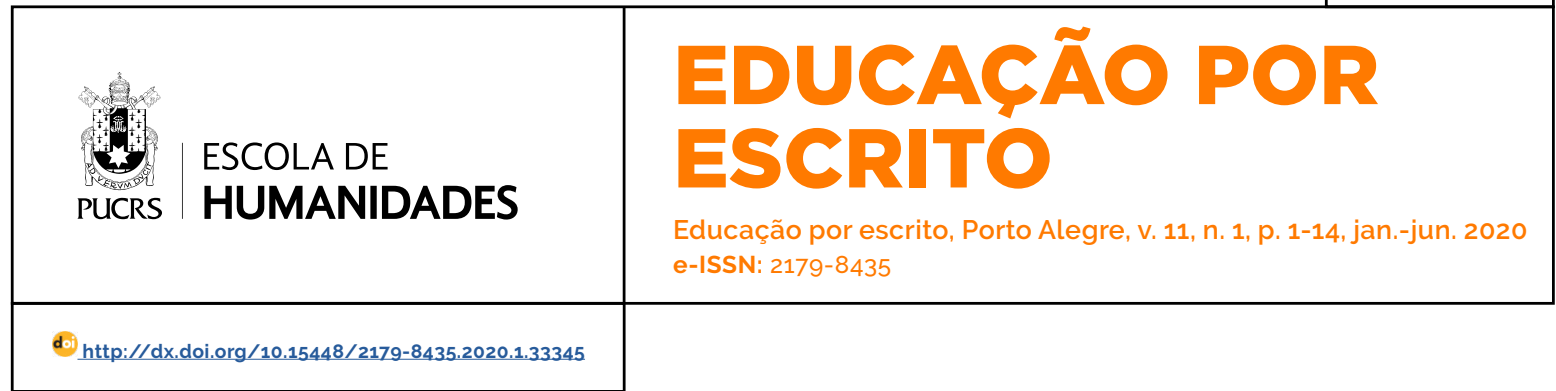

SEÇÃO: ARTIGOS

\title{
A experimentação na perspectiva de professores de Química da rede pública estadual de Porto Alegre
}

\author{
Experimental activities from the perspective of public high school of Chemistry teachers
}

\section{Lúcia Maria de Araujo Quevedo ${ }^{1}$ \\ orcid.org/0000-0003-4372-8328 \\ lucia.mquevedo@gmail.com}

\section{Andréia Modrzejewski \\ Zucolotto $^{1}$}

orcid.org/0000-0002-4889-5945 andreia.zucolotto@poa.ifrs.edu.br

Recebido em: 13 fev. 2019. Aprovado em: 8 jan. 2020. Publicado em: 27 jul. 2020.
Resumo: Esta pesquisa investigou como a trajetória dos professores de Química do ensino médio de escolas públicas estaduais de Porto Alegre favoreceu a apropriação e o desenvolvimento de atividades experimentais em sua prática docente. Apuraram-se suas concepções a respeito das contribuições da realização dessas atividades no ensino de Química. Definida como um estudo de caso, seu corpus de análise construiu-se pelas transcrições das entrevistas. Na interpretação dos dados, utilizou-se a análise textual discursiva (ATD) e emergiram tais categorias: a) a apropriação das atividades experimentais em suas trajetórias docentes, b) concepções docentes acerca da realização de atividades experimentais e c) a motivação para realização de atividades experimentais diante do cenário atual de ensino. As concepções para o desenvolvimento dessas atividades foram: aulas diferenciadas, receptividade e motivação dos alunos, instigação à curiosidade, auxilio na compreensão dos conceitos abstratos, respaldo da teoria e contribuição na aprendizagem e sua aplicabilidade no cotidiano. Os docentes se apropriaram dessas concepções durante sua formação escolar e, por influência de colegas reiterando o uso dessas atividades a fim de manter compromisso com a docência, o aluno e com uma educação de qualidade.

Palavras-chave: Atividades experimentais. Ensino de Química. Ensino médio.

Abstract: This study investigated how the trajectories of Chemistry teachers from public high schools in Porto Alegre influenced their choice and development of experimental activities in their teaching practices. We analyzed concepts incorporated by the teachers on the benefits of using these activities in Chemistry teaching. This is a qualitative, case study-based research. The corpus is composed of transcribed interviews. In order to analyze the data, we referred to discourse text analysis (DTA). After unitarization and categorization, the ensuing categories emerged: a) appropriation of experimental activities in teaching paths, b) teachers' concepts on the execution of these activities and c) motivation to use these activities considering educational scenario. The following concepts for the development of those activities were listed: special classes, students' receptivity and motivation; instigation of curiosity, aid in abstracting for comprehending concepts, theoretical background, and contribution to learning, recognizing and applying Chemistry in everyday life. Teachers adopted these concepts during their professional formation and by influence from colleagues. They highlight that using these activities demonstrate commitment to teaching, to the students and to high-quality education. Keywords: Experimental activities. Chemistry teaching. High school.

\section{A experimentação e a docência em Química}

As atividades experimentais estão associadas ao ensino de Química e essas perpassam o imaginário quando aulas dessa disciplina são referidas. Discussões realizadas sobre a utilização dessas práticas são encontradas na literatura da área (GALIAZZI et al., 2001; OLIVEIRA, 2010; DEL PINO; FRISON, 2011; CACHAPUZ et al., 2011) e contribuem para consolidar o 
tema e para argumentar sua adoção nas aulas de Química. Contudo, alguns docentes, por vezes, não utilizam essas atividades, tendo como justificativa o atual cenário do ensino público na rede estadual do Rio Grande do Sul, em que nem sempre os laboratórios apresentam condições de funcionamento e seus materiais são precários. Nesse contexto, foi realizada uma pesquisa com professores de Quimica da rede pública estadual de ensino médio no municipio de Porto Alegre em que, investigou-se o que pensam sobre experimentação esses docentes que adotam tais práticas em suas aulas, apesar do cenário conhecido e atualizado por meio do levantamento na etapa inicial desta pesquisa. Assim, decidiu-se retomar nessa investigação a temática da experimentação para compreender as concepções docentes acerca das contribuições dessas atividades nas aulas de Química. Entre os objetivos estão investigar quais são as concepções acerca da experimentação no ensino de Química e de que maneira a trajetória desses profissionais pode ter contribuido para a apropriação e o desenvolvimento dessas atividades em sua prática docente.

Nessa pesquisa, o termo experimentação foi utilizado como sinônimo à atividade experimental. Em âmbito escolar, entende-se a atividade experimental escolar como uma "prática educativa", denominada por:

[...] um conjunto de ações que determinam tanto o caráter preordenado de um ambiente de aprendizagem como a sua dimensão de construção social. Essa é fundada em certa concepção de aprendizagem desde a sua organização inicial, até a sua realização singular (MOREIRA; PEDROSA; PONTELO, 2011, p. 17).

Portanto, se faz relevante ao ensino de ciências na medida em que "possibilita aos alunos uma aproximação do trabalho científico e melhor compreensão dos processos das ciências" (ROSITO, 2003, p. 196). E, necessariamente, envolvem a interação entre o sujeito e o objeto de estudo, possuindo um caráter cognitivo capaz de articular os conhecimentos "atitudinais, procedimentais e conceituais" (OLIVEIRA, 2010, p. 141).

Logo, consideraram-se aqui todas as atividades experimentais que envolvam manipulação de um experimento sendo realizadas em laboratório ou em qualquer outra dependência da escola, utilizando materiais convencionais ou alternativos.

A pesquisa começou em 2016 com um levantamento inicial de todas as escolas públicas estaduais de Porto Alegre e constatou-se que as condições dos espaços oferecidos nas escolas apuradas, condizem com demais relatos da área (BUENO, 2007; BEREZUK; INADA, 2010; ANDRADE; MASSABNI, 2011) como insatisfatórias, devido à falta de material ou de manutenção dos laboratórios, permitindo apenas a realização de experimentos simples. Verificou-se que, apesar do cenário apurado, $44,2 \%$ dos docentes de Química das referidas escolas promoviam algum tipo de atividade experimental em suas aulas. Afora desse indice, estavam os professores que se encontravam em licença ou exercendo outras funções na escola, podendo resultar em um percentual maior.

Assim, mesmo diante das limitações estruturais e financeiras apresentadas, houve um esforço dos docentes em realizar tais práticas, o que nos levou a pesquisar o que os empreende a favor da adoção desse recurso didático em suas aulas. Quais seriam as concepções sobre a realização de atividades experimentais que permeiam esses professores? Como esses entendimentos foram constituídos? Ressalta-se que a pesquisa não objetivou fazer juizo de valores a respeito daqueles professores que realizam ou não atividades experimentais e sim procurou compreender as motivações dos docentes que promoveram esse tipo de atividade. Pretende-se coadjuvar no entendimento de como se consolidaram essas concepções sobre atividades experimentais tendo como aporte teórico os estudos de Tardif, Pozo e Crespo, entre outros.

A respeito das concepções docentes, Tardif (2014, p. 65) diz que:

[...] um professor não possui habitualmente uma
só e única concepção de sua prática [docente],
mas várias concepções que utiliza em sua prá-
tica [docente] em função, ao mesmo tempo de
sua realidade cotidiana e biográfica e de suas
necessidades recursos e limitações.

Logo, esse conjunto de concepções acerca das práticas docentes, vinculadas ao uso da 
experimentação, pode ter sido vivenciado durante a formação e/ou na sua ação cotidiana e ter sido incorporado a essas atividades no ensino de Química. Tardif (2014, p. 65) diz que os saberes dos professores possuem uma "coerência pragmática e biográfica". Assim, ao entrelaçar esses saberes experienciados sobre experimentação aos efeitos do uso dessas práticas observados nos estudantes, os professores estabelecem concepções que podem embasar a utilização dessas atividades.

Portanto, acreditamos que a articulação dos saberes de ensino de química às postulações de Pozo e Crespo, podem nos auxiliar a compreender como os professores entendem a experimentação e sua contribuição para a aprendizagem de Química.

\section{Delineando os caminhos percorridos}

Essa é uma pesquisa de caráter qualitativo, considerando o propósito de descrever um fenômeno e os sujeitos envolvidos em seu contexto natural. Nesse caso, ao fenômeno "experimentação" é atribuida à perspectiva de cada docente sobre ele e, a sua realização no âmbito escolar, como o seu ambiente natural. Para tanto, se fundamenta no paradigma qualitativo no campo construtivista-interpretativo, onde são "focadas as dinâmicas das interações humanas com ênfase no olhar sobre um fenômeno socialmente construido por múltiplas perspectivas" - a perspectiva de cada professor (DAL-FARRA; LOPES, 2013, p. 74). Tendo a experimentação como objeto de estudo, buscouse "compreender o comportamento e a experiência humanos [a fim de] entender o processo pelo qual as pessoas constroem significados e descrevem em que consistem estes mesmos significados" (BOGDAN; BIKLEN, 1994, p. 70).

Em consonância a esses aspectos, este estudo se articulou com a definição de pesquisa qualitativa de Minayo (2001, p. 14), definida como aquela que "trabalha com o universo de significados, motivos, aspirações, crenças, valores e atitudes, o que corresponde a um espaço mais profundo das relações, dos processos e dos fenômenos que não podem ser reduzidos à operacionalização de variáveis".

Participaram da pesquisa sete docentes de
Química de regiões distintas do município de Porto Alegre, da rede pública estadual de ensino, escolhidos após um levantamento censitário realizado em todas as escolas públicas estaduais de ensino médio do referido município, por se sobressairem no desenvolvimento de atividades experimentais em suas aulas. As entrevistas foram gravadas em áudio, tendo por base um roteiro semiestruturado. Empregou-se a análise textual discursiva (ATD) (MORAES; GALIAZZI, 2011) como metodologia para análise dos dados.

Após os processos de unitarização e categorização, emergiram categorias que correspondem à experimentação na perspectiva de professores de Química da rede pública estadual de Porto Alegre. As categorias descrevem "a apropriação das atividades experimentais em suas trajetórias docentes", enfatizando o perfil desses professores e como ocorreu a influência da experimentação na sua formação e/ou atuação. Quanto às "concepções docentes acerca da realização de atividades experimentais", os entrevistados opinam em relação às aulas experimentais, descrevendo os efeitos observados nos estudantes a partir do desenvolvimento dessas atividades, suas crenças sobre as contribuições promovidas por tais práticas e as relações estabelecidas pelo uso de experimentos no ensino de Química no cotidiano. A última categoria que emerge da análise coloca em evidência "a motivação para a realização de atividades experimentais diante do cenário atual de ensino", descrevendo o que incentiva os docentes para o desenvolvimento dessas atividades e sua relação com o ensino de Química. A fim de preservar o sigilo dos participantes da pesquisa, utilizou-se o seguinte código para cada docente entrevistado: PQ-1 a PQ-7, onde as letras PQ correspondem a Professor de Química e a numeração representa um número sequencial aleatório.

\section{A apropriação das atividades experimentais em suas trajetórias docentes}

Em relação ao perfil dos entrevistados, apurou-se que todos os sete docentes têm formação concluida na área de licenciatura em 
Química e, três docentes possuem, ainda, o bacharelado na área. Identificaram-se formações complementares, tais como: especialização em Engenharia de Polímeros, em Ciências Físicas e Química Industrial, Especialização em Lingua Brasileira de Sinais e um Mestrado. Todos possuem uma ampla experiência com tempo de docência entre 10 e 20 anos e, lecionam em sua maioria, por 40 horas semanais.

Os entrevistados já lecionaram para todos os anos do ensino médio e, também, em Ciências para o ensino fundamental. Atualmente, quatro docentes ensinam somente Química e os demais atuam ainda nas disciplinas de Física e Ciências.

Quanto à apropriação das atividades experimentais nas trajetórias docentes, identificou-se por meio da análise desenvolvida, que essas ocorreram desde a formação básica, pelas atividades práticas desenvolvidas, pela influência de professores, e foram se constituindo em momentos distintos durante licenciatura e, posteriormente, fortalecidos na docência, seja pelo ambiente escolar ou curriculo que favorecia tais atividades ou, pela influência de colegas. Todas essas vivências resultaram em um apego pela prática da experimentação.

A princípio, foi evidenciada sua origem na própria escolarização inicial dos entrevistados, representada pela narrativa: "eu estudei num colégio que tinha laboratório de Física, de Química e Biologia. E isso foi para a minha vida toda" (PQ-4. informação verbal²), ficando explicita a "predileção ou afinidade" para com essas práticas. O apreço a tais atividades remetem ao aspecto emocional, ao narrar a opção pela docência em Quimica por influência de professores que marcaram a memória dos entrevistados: "eu resolvi fazer Química por causa de uma professora que eu tive lá no ensino médio" (PQ-1, informação verbal' ${ }^{3}$ ) e também pela ênfase na realização de atividades experimentais ocorrida com a maioria dos docentes desde a graduação: "Na faculdade eu tive muito laboratório. Isso foi bem importante" (PQ-7, informação verbal ${ }^{4}$ ). "Eu fui monitora da cadeira de aulas práticas e criei um gosto pelas aulas práticas e isso facilitou com que eu tenha segurança para dar aulas práticas" (PQ-5, informação verbal ${ }^{5}$. Essa vivência denota a experiência adquirida pelos professores antes de se constituírem como tal, pois enquanto alunos já se encontravam imersos em seu futuro local de trabalho, o ambiente escolar (TARDIF, 2014). Essa imersão contribui para a aquisição de saberes que estão impregnados de "crenças, representaçõese certezas" (TARDIF, 2014, p. 20) que, posteriormente, podem vir a contribuir em sua prática docente.

Assim, as influências adquiridas durante a formação podem refletir na maneira de ensinar dos docentes pelo modo que essas práticas reverberaram em sua vivência escolar. Segundo Tardif (2014), "muitas pesquisas mostram que esse saber herdado da experiência escolar é muito forte, que ele persiste através do tempo e que a formação universitária não consegue transformá-lo nem muito menos abalá-lo" (2014, p. 20). O processo de apropriação do uso de atividades experimentais somou-se aos saberes que foram se consolidando durante a sua atuação docente, a partir das situações vivenciadas no cotidiano escolar. A respeito desses saberes, Del Pino e Frison (2011) dizem que:

Estes saberes são objetivados na prática cotidiana do professor mediante a conexão que este consegue estabelecer entre os diversos saberes com os quais tem contato em diferentes momentos ao longo da sua formação e com as concepções que embasam a sua prática pedagógica (2011, p. 48).

\footnotetext{
2 Depoimento do Professor de Química No 4 concedido à pesquisadora Lúcia na escola em que o professor atua, na cidade de Porto Alegre, RS, Brasil, no dia 10 do mês de julho do ano de 2017. Para evitar repetições e por não haver modificações a serem feitas, essa nota será aplicada em todas as referências relativas a $P Q-4$.

3 Depoimento do Professor de Química No 1 concedido à pesquisadora Lúcia na escola em que o professor atua, na cidade de Porto Alegre, RS, Brasil, no dia 19 do mês de julho do ano de 2017. Para evitar repetições e por não haver modificações a serem feitas, essa nota será aplicada em todas as referências relativas a $P Q-1$.

4 Depoimento do Professor de Química No 7 concedido à pesquisadora Lúcia na escola em que o professor atua, na cidade de Porto Alegre, RS, Brasil, no dia 13 do mês de julho do ano de 2017. Para evitar repetições e por não haver modificações a serem feitas, essa nota será aplicada em todas as referências relativas a $P Q-7$.

5 Depoimento do Professor de Química No 5 concedido à pesquisadora Lúcia na escola em que o professor atua, na cidade de Porto Alegre, RS, Brasil, no dia 17 do mês de julho do ano de 2017. Para evitar repetições e por não haver modificações a serem feitas, essa nota será aplicada em todas as referências relativas a $P Q-5$.
} 
A prática pedagógica também se constitui no ambiente escolar, o qual pode influenciar no desenvolvimento de atividades experimentais, se houver tal cultura na escola, o professor estará inclinado a fazê-lo tal como enunciado pelo $P Q-1$ que afirma: "eu comecei a dar aula em uma escola que tinha aulas práticas no cronograma o ano inteiro. [...] Eu tive essa rotina da escola e achei boa" (PQ-1, informação verbal). E mesmo quando esse cenário não é favorável, a pesquisa mostrou que ocorre a mobilização de ações docentes com intuito de colocar o laboratório em funcionamento: "No colégio que trabalhei o laboratório era um depósito. Eu arrumei o laboratório" (PQ-4, informação verbal).

Observou-se que a ausência de um laboratório interfere na realização dessas atividades pelos docentes: "Teve uma escola que não tinha laboratório e eu tive a vivência de dar só a parte teórica. Foi aquela coisa cansativa, o quadro cheio, aluno cansado e não rendia, eles não entendiam" (PQ-4, informação verbal). Entende-se a importância de um espaço destinado a essas atividades, contudo sua existência não é determinante para a realização dessas práticas. Esse aspecto poderia ser problematizado nos cursos de formação de professores, no que tange às condições de trabalho enfrentadas pelos docentes mobilizando o repensar para outras possibilidades. E remete a uma reflexão quanto à postura adotada para a realização ou não de experimentos com os alunos; ou seja, "isso é algo que precisa ser problematizado com os futuros docentes para, entre outros aspectos, não responsabilizar unicamente o professor pelo não desenvolvimento de atividades experimentais" (GONÇALVES; 2009, p. 156). No cotidiano do professor, por vezes, é inviável ficar carregando e organizando materiais de uma sala de aula para outra consecutivamente. Portanto, pode-se justificar a ausência de atividades experimentais nessas circunstâncias e a decisão de realizá-las ou não, em tal situação, deve ficar a critério do professor.

A socialização com seus pares também foi outro aspecto que influenciou na realização de atividades experimentais pelos entrevistados. Essa ocorreu gradativamente: "Fui aprendendo através de alguns encontros de professores de química. Aos poucos fui percebendo a importância disso" (PQ-4, informação verbal). Considera-se a troca de experiências como uma importante fonte de aprendizagem na medida em que contribui estruturação do saber profissional para o desenvolvimento da práxis docente. A partir da socialização de ideias e vivências promovidas, o professor pode consolidar suas concepções a respeito da realização de atividades experimentais no ensino de Química.

\section{Concepções docentes acerca da realização de atividades experimentais}

Muitas pesquisas já discorreram acerca das concepções docentes sobre a importância, as contribuições e os objetivos das atividades experimentais que amparam a sua aplicação no ensino de Química (GALIAZZI et al., 2001; GONÇALVES, 2009; OLIVEIRA, 2010). Elas reiteram que os docentes possuem fortes concepções a respeito da experimentação e, por vezes, se dispõem a enfrentar "situaçõeslimite"6 (GONÇALVES, 2009) vivenciadas em seu cotidiano escolar em prol da realização dessas atividades. Assim, apesar da recorrência do tema, a pesquisa se justificou ao atualizar o panorama da educação em Química no que diz respeito ao uso da experimentação em sala de aula e, ao apontar nas narrativas dos professores as concepções que os fazem optar por realizar tais atividades.

As análises apontaram para as seguintes subcategorias que inferem sobre as concepções docentes a respeito da realização de atividades experimentais: a experimentação contribui para que a aula seja diferenciada, dinâmica, motivadora e produtiva. Quanto às crenças, os docentes acreditam que as atividades experimentais instigam a curiosidade e favorecem a abstração dos conceitos auxiliando na comprovação da teoria: relação teórico-prática. $\mathrm{E}$, também, nas relações do ensino de Química com o cotidiano que podem

\footnotetext{
6 As situações-limites descritas por Gonçalves (2009) são aquelas dificuldades relacionadas à precariedade de recursos físicos e estruturais que o professor se depara em sua prática docente.
} 
ser promovidas por essas atividades coadjuvando para o desenvolvimento da aprendizagem.

Segundo os entrevistados, a aula experimental torna-se diferenciada à medida que possibilita aos estudantes sairem da rotina e interagirem em outro espaço. Eles se utilizam dessas atividades "pra diversificar as aulas, pra não ficar aquela coisa tão chata de teoria e exercicio" (PQ-1, informação verbal). Eles perceberam uma mudança na postura do aluno na realização dessas atividades: "toda vez que a gente faz uma aula prática, eles relaxam e não tem aquela reclamação geral de que é muita matéria" (PQ-5, informação verbal). E por considerarem a rotina de quadro e giz maçante - "É inadmissivel tu chegar e encher o quadro da sala de aula, explicar, explicar. É cansativo!" (PQ4, informação verbal) - optaram pela realização de tais práticas. Em sua maioria, alegam que a experimentação contribui para a receptividade dos alunos em relação às aulas: "A maioria dos alunos não gosta de Química porque é chato e tal... Levo para o laboratório e eles já começam a ter outra visão" (PQ-4, informação verbal). Além da reação dos alunos percebida pelos docentes na aplicação dessas aulas: "Tu vê isso pela reação deles, pelo entusiasmo, curiosidade e a necessidade que eles têm de registrar em fotos a aula prática" (PQ-5, informação verbal).

Entretanto, mesmo com o entusiasmo discente evidenciado, muitas vezes, a receptividade pode estar mais associada à mudança de ambiente do que à proposta de aula prática em si: "Os alunos gostam de ir para o laboratório. Mas eles fazem uma festa! Eles não vão para o laboratório com o intuito de fazer a relação teórico-prática. Eles vão para ter um outro ambiente" (PQ-2, informação verbal7). Apesar de vários professores reiterarem em seu entendimento que as atividades experimentais são motivadoras, outros fazem o contraponto. Alguns consideram que tais práticas têm capacidade de promover o interesse nos estudantes: "Eu percebo que o aluno se interessa. Desperta o interesse nos alunos" (PQ-6, informação verbal $\left.^{8}\right)$. No entanto, a opinião entre dos docentes não é unânime, já que alguns professores dizem que "tem exceções que às vezes não gostam" (PQ-1, informação verbal), mostrando realidades diferentes no contexto em que atuam.

Ao considerar que os estudantes possuem interesses e habilidades distintas para as atividades, é possivel impactar na predisposição para o desenvolvimento das mesmas, pois "nem sempre as atividades experimentais são motivadoras para os alunos" (GALIAZZI et al., 2001, p. 254). Nesse viés, Pozo e Crespo (2009, p. 41) dizem que os estudantes mobilizam seus interesses para coisas diferentes daquelas que o professor pretende. A desmotivação do aluno pode estar relacionada à insegurança na manipulação dos materiais, de interagir com o grupo ou por ele simplesmente não se sentir atraido por esse tipo de atividade. Logo, por mais empenho que o docente possa ter para com a promoção de tais práticas, o resultado pode não ser refletido no envolvimento do aluno. Da mesma forma:

\begin{abstract}
Determinada atividade pode caracterizar alto grau de envolvimento e participação dos indivíduos; pode ser atraente, provocativa e até mesmo divertida, mas, se o entendimento da mensagem - o conceito ou a teoria - não se efetivar, se o resultado alcançado não promover o desenvolvimento do ser, a atividade não foi educativa (MOREIRA; PEDROSA; PONTELO, 2011, p. 24).
\end{abstract}

Percebe-se, então, a importância da reflexão da ação docente ao avaliar a prática proposta durante todo o seu desenvolvimento. Se o estudante tem dificuldade para entender e não acompanhar a atividade, e isso passar despercebido em sala de aula, é possivel que ele efetivamente perca o interesse. Segundo Pozo e Crespo (2009, p. 17): "em consequência do ensino recebido os alunos adotam atitudes inadequadas [...] que se traduzem em uma falta de motivação e interesse

\footnotetext{
7 Depoimento do Professor de Química No 2 concedido à pesquisadora Lúcia na escola em que o professor atua, na cidade de Porto Alegre, RS, Brasil, no dia 04 do mês de agosto do ano de 2017. Para evitar repetições e por não haver modificações a serem feitas, essa nota será aplicada em todas as referências relativas a PQ-2.

8 Depoimento do Professor de Química No 6 concedido à pesquisadora Lúcia na escola em que o professor atua, na cidade de Porto Alegre, RS, Brasil, no dia 12 do mês de julho do ano de 2017. Para evitar repetições e por não haver modificações a serem feitas, essa nota será aplicada em todas as referências relativas a PQ-6.
} 
pela aprendizagem desta disciplina". Enfim, "a motivação em sala de aula é um fenômeno complexo para ter a sua discussão encerrada em torno da experimentação" (GONÇALVES; MARQUES, 2011, p. 841), ainda assim, ela é enunciada por muitos docentes que adotam tais práticas nas aulas de Quimica, seja por trazerem resultados positivos ou, pela crença presente na cultura dos professores da área, mostrando que sua problematização se faz necessária.

Como meio de atingir interesses distintos, sugere-se aliar diferentes tipos de atividades: de laboratório, demonstrativas, investigativas, envolvendo situações-problema, de pesquisa por experimentos, por projetos, com o intuito de compreender as distintas formas de aprendizado. Pode-se denominar como democratização do saber a possibilidade de o aluno entender a experimentação em diferentes perspectivas. Diversificar metodologicamente as práticas, colocando o aluno na produção ativa das mesmas, pode contribuir para a autonomia e para o desenvolvimento do espirito investigativo e instigar sua curiosidade latente:

É uma curiosidade natural que todas as crianças nascem com isso. Essa curiosidade inata, a escola acaba matando, o que é contraditório, né? A escola tem o objetivo de ensinar, desenvolver os alunos. Mas mata a curiosidade do aluno e ele acaba não se desenvolvendo (PQ-6, informação verbal).

Quando "a curiosidade é domesticada lé possivell a memorização mecânica deste ou daquele objeto, mas não o aprendizado real ou conhecimento cabal do objeto. A construção ou produção do conhecimento implica no exercício da curiosidade" (FREIRE, 1996, p. 95). Para os docentes, a experimentação se revela como um ponto de partida para instigar a curiosidade do aluno. Contudo, sugere-se que, durante o processo, se estabeleçam diálogos para direcionar essa curiosidade à reflexão, às hipóteses e ao desenvolvimento da argumentação. Ao se incentivar o debate durante a atividade, pode-se oportunizar a proposição de ideias e contribuir para que o docente avalie seu aluno e a sua própria prática.

Outro aspecto abordado a respeito da atividade experimental concerne à abstração de conceitos da Química. A compreensão das interações existentes entre as substâncias e o modo como se comportam e desencadeiam fenômenos é complexa ao entendimento dos alunos. "Ela é muito abstrata e trata de coisas minúsculas, que não se consegue ver ou tocar, mas que existem" (PQ-3, informação verbal ${ }^{9}$. Segundo Vygotsky (2000 apud DIAS et al., 2014, p. 495):

O estabelecimento de relações lógicas pelas quais certos elementos podem ser agrupados e dar origem a um conceito expresso por um signo verbal somente ocorre por volta dos doze anos. Depois desse período o pensamento alcança um desenvolvimento adequado para obter uma melhor compreensão de todas as situações do mundo e trabalhar abstratamente.

Mesmo que para Vygotsky os adolescentes já tenham a habilidade de abstrair, pois é um processo que eles vão desenvolvendo desde a infância com as interações estabelecidas em sua vivência, com a Química essa abstração tornase dificil, pois eles não pensam em como ela se manifesta durante a sua infância. A Quimica, suas relações com o mundo e com eles, só thes são apresentadas a partir do início da adolescência e, para que os estudantes consigam abstrair de modo a compreendê-la, é necessária uma gradativa interação com o objeto - o fenômeno - a fim de the atribuir significado, o que por vezes não é possivel e, talvez por isso haja dificuldade de um raciocinio lógico-abstrato quanto ao tema. Dai a necessidade de ver, tocar, para estabelecer relações e elaborar conhecimentos: "Eu preciso mostrar coisas que eles consigam tocar, reações que eles consigam ver. Porque os meus alunos têm dificuldade com teoria" (PQ-5, informação verbal); que foi observada como uma concepção comum aos docentes.

Além disso, a abstração requer articulação entre a linguagem para atribuir significado ao

9 Depoimento do Professor de Quimica No 3 concedido à pesquisadora Lúcia na escola em que o professor atua, na cidade de Porto Alegre, RS, Brasil, no dia 10 do mês de julho do ano de 2017. Para evitar repetições e por não haver modificações a serem feitas, essa nota será aplicada em todas as referências relativas a PQ-3. 
que é real e, esse processo se desenvolve progressivamente, sofrendo modificações e alterações conforme as relações que se estabelecem entre o individuo e o mundo. Conforme Cruz (2005, p. 1):

Na perspectiva da psicologia histórico-cultural de Vygotsky, o conhecimento do mundo é sempre mediado pelas práticas culturais, pelo outro e, especialmente, pela linguagem. Pela palavra, na relação com o outro, referimo-nos ao mundo, classificando, recortando, agrupando, representando, significando, enfim, o real.

Esse é outro obstáculo, pois a Quimica tem uma linguagem própria que demanda tempo para ser incorporada e estruturada pelos estudantes (POZO; CRESPO, 2009). São competências especificas, que requerem do aluno habilidades particulares e, mesmo em exigência progressiva, apresentam certo grau de complexidade que, por vezes, o estudante não consegue desenvolver. Nesse sentido, o aluno:

Ao defrontar-se com um grande número de leis e conceitos novos fortemente abstratos, estabelecer conexões entre esses conceitos e entre os fenômenos estudados e, como se fosse pouco, deparam-se com a necessidade de utilizar uma linguagem altamente simbólica e formalizada, junto com modelos de representação analógicos que ajudem a representar aquilo que não é observável (POZO; CRESPO, 2009, p. 140).

Observada essa dificuldade discente pelos docentes, foi evidenciado que as atividades experimentais contribuem para o entendimento de alguns conceitos em que era necessária a abstração: "Só com a experimentação é que eles conseguiam visualizar melhor a matéria, o conteúdo era muita teoria e eu vi que não atingia o objetivo. E quando eu conseguia fazer uma experiência surtia efeito" (PQ-7, informação verbal). Essa situação pode ter colaborado para a necessidade que os docentes têm de aliar a teoria à prática.

Por esse motivo, geralmente eles desenvolvem suas aulas com intuito de estabelecer uma relação teórico-prática e as realizam da seguinte maneira: Ela tem dois momentos: "o primeiro é dentro da sala de aula que eu explico toda a parte teórica [...], e depois o segundo momento é dentro do laboratório" (PQ-4, informação verbal). Em seu entendimento, essa abordagem metodológica, permite ao aluno relacionar o conteúdo teórico com o prático: "Eu acho que a aula experimental sempre reforça o conteúdo didático que a gente deu em aula, a teoria. Então na prática eles vêem o que acontece na teoria" (PQ-1, informação verbal). Segundo os entrevistados, a atividade experimental contribui para respaldar a teoria: "Eles conseguem ligar a parte do conteúdo - a parte teórica - fica muito mais embasada" (PQ-3, informação verbal) e, também, para favorecer o entendimento dos estudantes acerca do tema trabalhado: "Se tu não tem o teórico e o prático, a compreensão fica comprometida" (PQ-2, informação verbal). Eles atribuiram essa concepção como uma característica do docente de Quimica: "Todo professor de Química tem essa necessidade de mostrar, de demonstrar pro aluno que aquilo ali é verdadeiro, não é teórico" (PQ-2, informação verbal).

Essa concepção sobre a natureza pedagógica da experimentação com a finalidade de comprovação da teoria é muito arraigada nos professores da área de Ciências e, na Química, encontra-se mais enraizada, especialmente, pela semelhança na formatação curricular dos cursos de licenciatura e do bacharelado (SILVA et al., 2009). E, apesar dessa mudança já ocorrer em alguns cursos, os professores formadores ainda precisam se adaptar a esses currículos diferenciados. Nesse sentido, enfatizam "a necessidade de discutir a experimentação como artefato pedagógico em cursos de Química, pois alunos e professores têm teorias epistemológicas arraigadas que necessitam ser problematizadas" (GALIAZZI; GONÇALVES, 2004, p. 326). A sintese está em se reconhecer a natureza pedagógica da experimentação a partir do seu perfil epistemológico no que se refere a sua concepção de ciência. O caráter reflexivo é preponderante para o desenvolvimento da prática docente. Esua discussão é necessária para que, desde o seu processo formativo, o licenciando em Química possa se desvincular do empirismo ingênuo, cuja visão de Ciência é entendida como uma observação neutra, comprobatória, de verdades absolutas e imutáveis (GONÇALVES, 2009). 
Ademais, o tempo destinado em aula para a realização de uma atividade experimental não é suficiente para comprovar uma teoria (GALIAZZI; GONÇALVES, 2004), quiçá estruturar seus conhecimentos aos novos construidos pela simples comprovação, já que concepções prévias - especialmente as errôneas - não são abandonadas assim, de imediato. A "forma como os alunos habitualmente entendem os fenômenos científicos, [...] se tratam com frequência, de concepções muito persistentes que praticamente não se modificam após muitos anos de instrução científica" (POZO; CRESPO, 2009, p. 15).

Para tanto, o professor pode articular diferentes recursos didáticos para complementar a atividade desenvolvida, a fim de contribuir na apropriação dos conhecimentos trabalhados intermediando as ações com os conceitos envolvidos.

Outro tópico a respeito das concepções docentes envolveu o uso da experimentação para promoção da aprendizagem. Nesse aspecto, a opinião docente foi unânime, seja pela "facilitação": "O quanto um professor pode facilitar para o aluno a aprendizagem senão com uma aula prática?" (PQ-5, informação verbal), ou como aspecto positivo relacionado: "O ponto positivo é esse: um aprendizado melhor" (PQ1, informação verbal), ou pela apreciação dos alunos: "Ele acaba gostando da disciplina. Isso me motiva a dar aulas práticas, dai eles vão aprender o conteúdo" (PQ-7, informação verbal).

São muitos os condicionantes para a aprendizagem, como a predisposição do aluno, que envolve a atenção e a sociabilidade para participar da aula, a relação entre professor e aluno para que esse se sinta à vontade de esclarecer dúvidas, assim como fatores econômicos que inferem sobre a qualidade de vida e a aprendizagem, como saúde e alimentação e, por fim, condições psicológicas que envolvem os relacionamentos familiares.

Contudo, não é o objetivo deste artigo discorrer sobre esses aspectose, no que tange a contribuição da atividade experimental para esse fim, infere-se tão somente que ela pode sim ser coadjuvante. Entretanto, a atividade experimental por si só não garante o aprendizado. A aprendizagem não é somente fomentada pela ação docente. Há outros fatores já mencionados que são agregados a ela. Mas a forma que o professor desenvolve a atividade, conduzindo-a conforme os objetivos planejados podem contribuir para que a aprendizagem se torne significativa, permeada por um processo constante de ação-reflexão de sua prática. Acrescentando a esses fatores, a aprendizagem de Química envolve também a mudança epistemológica, pois "compreender a Química envolveria uma mudança na lógica a partir da qual o aluno se organiza" (POZO; CRESPO, 2009 p. 142). Isso implicaria na modificação de concepções alternativas que os estudantes podem ter a respeito de fenômenos ou da natureza epistemológica que eles possuem sobre Ciência.

A aprendizagem abrange a "mudança conceitual (ontológica)" e pressupõe quebras de paradigmas para a reestruturação de novos conhecimentos "quando existe uma incompatibilidade entre a teoria científica e a que é mantida pelo aluno" (POZO; CRESPO, 2009, p. 102). E, compreende na mudança dos conceitos envolvidos a partir da abstração de propriedades, da existência de processos e transformações previstos pelo fenômeno, "tornase necessário compreender a matéria como um complexo sistema de partículas em contínua interação, com propriedades que se conservam em equilibrio" (POZO; CRESPO, 2009, p. 142).

Também foi comum entre os docentes a relação da atividade experimental com foco na aplicabilidade do ensino de Química no cotidiano: "Nas minhas aulas experimentais, [...] eu quero que eles enxerguem não só a parte teórica da Química, mas a parte da aplicabilidade no dia dele" (PQ-2, informação verbal). Essa preocupação denota o compromisso docente com a educação para além da sala de aula, para a vida. Pode ser difícil entender o cientificismo que envolve a Química, mas com essas ações é possivel aproximá-la do comum, do que é humano. Mostrar como ela se apresenta na simplicidade da vida para o aluno pode resultar que sua compreensão não seja tão distanciada do que se faz presente. "A ideia é que ele consiga ver onde tem Química em volta dele. 
Eu não quero que ele vá até o laboratório buscar a Química, mas que enxergue o quão próximo dele a Química está" (PQ-3, informação verbal).

Assim, "quando a experimentação é desenvolvida juntamente com a contextualização, ou seja, levando em conta aspectos socioculturais e econômicos da vida do aluno, os resultados da aprendizagem poderão ser mais efetivos" (SILVA et al., 2009, p.

2). Observando esses aspectos, os professores se utilizam de métodos nos quais contextualizam os conhecimentos químicos para práticas cotidianas dos alunos: "a gente tenta utilizar métodos [...] que eles vivenciam [...] porque isso reflete diretamente no cotidiano deles" (PQ-5, informação verbal).

Articular os conhecimentos da Química com o cotidiano relacionando aos saberes vivenciados no dia a dia, pode contribuir para que esses sejam reconhecidos e aplicados em outras situações pelos estudantes. Para tanto, essas atividades podem ser direcionadas à "solução de pequenos problemas, mais próximo da realidade cotidiana, nos quais o aluno possa pôr em prática alguns dos procedimentos de trabalho da Ciência, o que, por sua vez irá ajudá-lo a aprender Química" (POZO; CRESPO, 2009, p. 185). Dessa forma, o ensino de Química, aliado às atividades experimentais que contextualizam ações cotidianas, auxilia a aproximar a Química dos alunos ao "mostrar no dia a dia o que acontece, na vida deles, [...] para eles entenderem melhor a Química (PQ-7, informação verbal). [...] pra eles enxergarem na prática o que acontece em tudo" (PQ-1, informação verbal). Nesse contexto, Del Pino e Frison (2011, p. 40-41) dizem que:

Aproximar a realidade criada pela ciência da realidade da vida cotidiana, a linguagem cientíica da linguagem cotidiana. Promover um diálogo entre as teorias científicas e os fenômenos em estudo, entre os principios científicos e os contextos sociais e tecnológicos em que eles se materializam. Isso torna a ciência escolar mais interessante e com mais significado para a maioria dos estudantes.

Isso pode contribuir para que os alunos possam ter outra visão de ciência do que aquela rotulada pela sociedade. "Essas atividades experimentais dão uma visão melhor do sentido de ciência, o que acontece com aquelas reações, com aquele fenômeno. A prática sempre é bem-vinda nesse sentido" (PQ-2, informação verbal). Cabe destacar que as funções distintas em que a experimentação pode ser aplicada acompanham as concepções de ciência para a qual ela foi produzida. Assim, as atividades experimentais realizadas nas escolas se diferenciam dos demais experimentos realizados em outras instituições de ensino e de pesquisa pelos objetivos que buscam ser alcançados (OLIVEIRA, 2010).

Ao exemplificar situações cotidianas onde o caráter científico possa ser vinculado, o docente possibilita ao estudante essa aproximação com a ciência de modo que ele possa reconhecer as distintas maneiras de se fazer ciência. Por isso, o diálogo em sala de aula é um agente mobilizador na mediação de ideias. A maneira como esse aspecto é abordado também pode contribuir para o entendimento dos alunos no que se refere à temporalidade do saber científico e à mutabilidade da ciência. "Descobriram um negócio novo hoje sobre aquilo que vocês viram na aula passada. Então a ciência não é exata, não é rígida. A ciência é história, ela tá acontecendo" (PQ-3, informação verbal).

É necessário que os estudantes tenham o caráter dinâmico do conhecimento científico "conseguindo que percebam sua transitoriedade e sua natureza histórica e cultural, que compreendam as relações entre o desenvolvimento da Ciência, a produção tecnológica e a organização social" (POZO; CRESPO, 2009, p. 21), reconhecendo o compromisso da ciência com a sociedade. Para isso, "a ciência deve ser ensinada como um saber histórico e provisório" (2009, p. 21) que está sempre se reconstruindo a partir de novos fatos.

Mostrar a relatividade do conhecimento científico
e que a ciência não é um corpo de conhecimento
acabado, mas é dinâmico. As suas teorias estão
sempre sujeitas a refutações. Portanto, aprender
Química é também aprender sobre a natureza
dessa ciência, seus processos de investigação
e seus métodos de construção e validação do
conhecimento (DEL PINO; FRISON, 2011, p. 40).

Estabelecer a relação da historicidade da ciência e da transitoriedade do saber é importante para que o aluno perceba que 
são pessoas comuns que fazem da ciência o que ela é e, por isso, ela também é passivel de erros. E, para consolidar essa nova visão de ciência nas escolas, é pertinente fomentar a discussão sobre os objetivos de ensinar ciências para os estudantes nos cursos de formação de professores nas áreas de ciências da natureza. O ensino de ciências para se caracterizar como algo construtivo, pode amparar seu aprendizado na interpretação de conceitos científicos que auxiliem na transposição desses conhecimentos para o entendimento e a resolução de situações vivenciadas. Nesse sentido, há uma preocupação docente em reverberar esse conhecimento para o mundo: "tu prepara o aluno para que ele possa no futuro seguir estudando, [...] que ele seja autônomo, seja questionador, seja inquieto em relação ao conhecimento" (PQ-3, informação verbal); promovendo no aluno um entendimento além da compreensão de fenômenos e conceitos envolvidos, pois contribui para que ele construa seus conhecimentos e aplique-os a situações vivenciadas, além de auxiliar na consolidação de seu perfil epistemológico no que concerne a sua visão de ciência. Percebeu-se nos aspectos apontados a motivação docente diante da realização de tais práticas.

\section{A motivação para realização de atividades experimentais diante do cenário atual e ensino}

A partir das contribuições elencadas pelos docentes a respeito da realização de atividades experimentais, percebeu-se a relevância desse recurso didático para o ensino de Química. Diante das condições já mencionadas em artigos da área e reafirmadas nessa pesquisa, alguns professores, considerando suas concepções a respeito da realização de atividades experimentais enfrentam as adversidades e as implementam em suas escolas. Assim, indagou-se sobre o que motiva esses docentes para a prática de tais atividades, para além das concepções descritas. Nessa nova categoria, emergiram as seguintes subcategorias que descrevem tais motivações: a promoção de uma educação de qualidade, o compromisso com a docência e com os alunos e, a paixão pelo o que fazem.

Inicialmente, o que os conduz para promoção dessas práticas é a possiblidade de oportunizar uma educação de melhor qualidade. Nesse sentido, eles priorizam o ensino de competências e habilidades, e não somente o conteúdo: "Então eu quero que eles tenham qualidade e não quantidade" (PQ-3, informação verbal). Esse comprometimento docente com o ensino vai de encontro com o descaso com a educação em nosso País: "realmente nós vivemos em um país que o ensino não é visto como algo sério" (PQ-6, informação verbal). Assim, os professores procuram fomentar em seus alunos a criticidade para o cenário educativo vivenciado: "eu tento fazer com que eles enxerguem que a formação deles é muito limitada" (PQ-3, informação verbal); com intuito de que o esforço docente com o ensino de qualidade reverbere para que os discentes exijam uma educação melhor: "Quanto mais eu fizer, mais os alunos vão querer reivindicar esse ensino. Mesmo que seja difícil, [...] eu acho que isso é importante" (PQ-2, informação verbal). Para esses docentes, a aula experimental e tudo que a envolve, também é um modo de qualificar o ensino.

De acordo com Lima, (2012, p. 97):

\section{A Quimica proporciona o exercício do raciocínio, principalmente aquele relacionado aos direitose deveres dos cidadãos, dando-lhes capacidades de exigir da sociedade e dos governos atitudes sensatas e corretas que melhorem nossa vida efetivamente.}

Considera-se importante um equilibrio entre o ensino formal e o da cidadania. Um deve estar relacionado ao outro, sem que se percam os seus objetivos. E ter a clareza de que ambos necessitam coexistir para formação de um cidadão pleno de seus direitos e deveres.

Nesse contexto, os docentes persistem na crença em um trabalho contínuo, com responsabilidade ética em apresentar um ensino de qualidade dentro das possibilidades vivenciadas, buscando que essas ações frutifiquem no desenvolvimento dos estudantes: "Não existe perspectiva hoje, mas a gente pode 
tentar fazer [...] tentar melhorar, tentar ajudá-los a superar as dificuldades" (PQ-6, informação verbal).

Em subsequente, constatou-se o compromisso em desempenhar bem seu papel de professor como mais uma motivação ao realizar experimentos com os seus alunos: "Eu tenho que cumprir meu papel de professora. Independente do que aconteça, eu continuo sendo professora e nem por isso eu vou fazer um trabalho ruim. Eu faço o que posso" (PQ-1, informação verbal).

Tal atuação docente é justificada com a satisfação que têm por ensinar, compreendida na escolha da profissão, no interesse e na dedicação aos alunos: "A motivação é minha no sentido de que eu gosto de fazer o que eu faço. Mas eu só gosto de fazer o que eu faço porque uma sala de aula vazia, uma escola vazia: não me serve. Eu tenho um único foco: os alunos" (PQ-3, informação verbal). Logo, os entrevistados se sobressaíram em suas práticas docentes pelo empenho que têm em desempenhar bem suas funções no que se refere tanto ao comprometimento firmado com seus alunos quanto com o apreço que possuem pela Química, resultando em outra motivação: "É que eu sou apaixonada pela Química. Eu tenho aquela ilusão, aquela vontade que o ensino de Química fosse levado a sério" (PQ-2, informação verbal). Da mesma forma, ao ensinar, tentam transpor essa paixão aos alunos: "As aulas experimentais vêm também para abrir os horizontes mostrando o quão linda a Química é, para eles se apaixonarem" (PQ-5, informação verbal).

Pode-se inferir que esses docentes tiveram em sua formação elementos que fortaleceram sua crença na realização de atividades experimentais à medida que vivenciaram as benesses de tais práticas, justificando, assim, a motivação e o apreço que têm em ensinar Química utilizando tais atividades mesmo com recursos escassos. Ou seja, identifica-se uma cultura da experimentação na concepção do que seja estudar Química para esses docentes.

Essa é representada no desabafo docente final que, expressa todo o sentimento que o motivou a ensinar Química e, em especial, a realizar atividades experimentais. Enfatiza-se que se optou por manter a fala inteira, em função do significado que a mesma representa no contexto da pesquisa, e a potencialidade que possui para sintetizar essa prática:

Bah, a gente chega até a se emocionar, né? $\mathrm{Na}$ verdade, o motivo é o aluno. Tu sabe que aluno de periferia não vai ter de repente a oportunidade de entrar em um laboratório. De ter, uma professora que vá preparar aula para ele...(De laboratório) Então muitos que sairam daqui, estão de caixa de mercado, estão trabalhando em balcão de farmácia... e muitos professores que disseram: para quê que eu vou me interessar em fazer isso, se ele vai ser caixa de mercado? Então tu tem que ter essa visão: Eu tô aqui, eu escolhi esta profissão e vou seguir até o fim; independente do que o aluno for ser. Lá no fundo ele vai lembrar... eu tive uma professora que fez algumas aulas diferenciadas... sempre fica alguma coisa, né? Aquela semente que tu planta ali, vai germinar. E é isso, é amor a profissão! Não tem outra coisa. Não é governo que vai te estragar. Não é salário parcelado. É amor a profissão! (PQ-4, informação verbal).

\section{Considerações finais}

A pesquisa buscou averiguar as concepções docentes acerca da realização de atividades experimentais nas aulas de Química nas escolas públicas estaduais do municipio de Porto Alegre, e identificou que, mesmo diante do cenário atual de precariedade da educação pública no que tange às condições dos espaços destinados a essas atividades, há uma resiliência dos docentes para a implementação de tais práticas. Observouse que tal resiliência está vinculada as suas concepções, constituídas desde o periodo de sua formação inicial, seja pelas suas vivências enquanto ainda alunos, no ensino médio - quando estabeleceram o primeiro contato com essas atividades - e transcorreram até a graduação e nas demais vivências na Química. Esses docentes conviveram com a experimentação, marcando sua formação de tal maneira que fizeram optar pela docência em Química e pela adoção dessas práticas em suas aulas. E, conforme sua atuação, essas concepções foram se consolidando, seja pela influência de colegas no ambiente escolar ou mesmo durante as práticas pelos resultados percebidos nos seus alunos.

Emergiram as seguintes concepções com relação às contribuições sobre o desenvolvimento 
de atividades experimentais em suas aulas de Química: a promoção de aulas diferenciadas, a receptividade dos alunos, desperta o interesse e motivação nos estudantes, instiga a curiosidade, contribui para o desenvolvimento do raciocínio abstrato para compreensão dos conceitos, estabelece relações teórico-práticas, fomenta a aprendizagem e favorece reconhecimento e aplicabilidade da Química no cotidiano. Suas narrativas estão de acordo com o que narram Bueno et al. (2007), sobre o que é atribuido ao desenvolvimento dessas atividades pelos docentes:

Pode-se observar com professores, que perguntas sobre a função e a importância da experimentação na ciência, levam a três tipos básicos de resposta: as de cunho epistemológico, que assumem que a experimentação serve para comprovar a teoria, revelando a visão tradicional de ciências; as de cunho cognitivo, que supõem que as atividades experimentais podem facilitar a compreensão do conteúdo; e as de cunho moto-vocacional, que acreditam que as aulas práticas ajudam a despertar a curiosidade ou o interesse pelo estudo (2007, p. 4).

Ao se discorrer sobre essas concepções, é pertinente refletir sobre a formação desses professores e, nesse aspecto, "uma maneira de transformar a formação de professores seja pela reflexão sobre as concepções dos formadores e dos futuros professores" (GALIAZZI et al., 2001, p. 250). Reitera-se a relevância de se promover nos cursos de licenciatura discussões sobre o caráter epistemológico da ciência que auxiliem os licenciandos na estruturação do seu perfil docente e, a partir dele, construam sua práxis, visando aprimorar seus conhecimentos e validar suas ações pela concepção de ciência ao qual se identificam (DEL PINO; FRISON, 2011).

Assim, apesar das limitações que vivenciam no seu cotidiano escolar, constatou-se que os docentes se esforçam no desempenho de suas funções para com a realização de atividades experimentais com seus alunos. Seja pela preocupação em relação à qualidade do ensino público, motivo pelo qual se empenham na realização de aulas diferenciadas ou, a partir de sua escolha profissional consolidada no comprometimento com a educação, zelo pelos alunos e apreço ao que fazem. Tais professores entendem a Química como uma atividade prática e transformam isso em uma cultura presente em suas aulas.

\section{Referências}

ANDRADE, M. L. F.; MASSABNI, V. G. O desenvolvimento de atividades práticas na escola: um desafio para os professores de ciências. Ciência \& Educação, Bauru, v. 17, n. 4, p. 835-854, 2011. Disponível em: http://Www.scielo.br/pdf/ciedu/v17n4/ a05v17n4.pdf. Acesso em: 24 nov. 2017. https://doi. org/10.1590/S1516-73132011000400005.

BEREZUK, P. A.; INADA, P.; Avaliação dos laboratórios de ciências e biologia das escolas públicas e particulares de Maringá, Estado do Paraná. Acta Scientiarum: Human and Social Sciences, Maringá, v. 32, n. 2, p. 207-215, 2010. Disponivel em: http://periodicos.uem.br/ojs/index.php/ActaSciHumanSocSci/ article/view/6895/6895. Acesso em: 02 dez 2017 https://doi.org/10.4025/actascihumansoc.v32i2.6895.

BOGDAN, R.; BIKLEN, S. K. Investigação qualitativa em educação: uma introdução à teoria e aos métodos. Porto, Portugal: Editora Porto, 1994.

BUENO, L. et al. O ensino de química por meio de atividades experimentais: a realidade do ensino nas escolas. In: ENCONTRO DO NÚCLEO DE ENSINO DE PRESIDENTE PRUDENTE, 2., 2007, Presidente Prudente. Anais do II Encontro do Núcleo de Ensino de Presidente Prudente. Presidente Prudente, UNESP, 2007

CACHAPUZ, A. et. al. A necessária renovação do ensino de ciências. 3. ed. São Paulo. Cortez, 2011.

CRUZ, M. N. Desenvolvimento cognitivo em Vygotsky: "entre os ideais da matemática e a harmonia da imaginação". Universidade Metodista de Piracicaba - UNIMEP; SP. In: REUNIÃO ANUAL DA ANPED, 2005. Disponivel em: http://28reuniao.anped.org.br/C: $\backslash$ Users $\backslash i c c i b \backslash D o w n l o a d s \backslash w w w . u n i m e p . b r \backslash \sim m n c r u z \backslash$ desenvolvimento-cognitivo-28-anped.pdf. Acesso em: 28 dez. 2017

DAL-FARRA, R. A; LOPES, P. T. C. Métodos mistos de pesquisa em educação: Pressupostos teóricos. Nuances: estudos sobre Educação, Presidente Prudente, v. 24, n. 3, p. 67-80, set./dez. 2013. Disponivel em: http://dx.doi.org/10.14572/nuances.v24i3.2698. Acesso em: 19 nov. 2017.

DEL PINO, J. C.; FRISON, M. D. Química: um conhecimento científico para a formação do cidadão. Revista de Educação, Ciências e Matemática, Rio de Janeiro, v. 1, n. 1, ago./ dez. 2011. Disponivel em: http://publicacoes.unigranrio.edu.br/index.php/recm/article/ view/1585/769. Acesso em: 19 nov. 2017

DIAS, M. S. L. et al. A formação dos conceitos em Vigotski: replicando um experimento. Revista Quadrimestral da Associação Brasileira de Psicologia Escolar e Educacional, São Paulo, v. 18, n. 3. p. 493-500, set./ dez. 2014. Disponivel em: http://dx.doi.org/10.1590/21753539/2014/0183773. Acesso em: 13 fev. 2019. 
FREIRE, P. Pedagogia da autonomia: saberes necessários à prática educativa. 19. ed. São Paulo: Paz e Terra, 1996.

GALIAZZI, M. C. et al. Objetivos das atividades experimentais no ensino médio: a pesquisa coletiva como modo de formação de professores de ciências. Ciência \& Educação, Bauru, v. 7, n. 2, p. 249-263, 2001. Disponivel em: http://dx.doi.org/10.1590/S151673132001000200008 . Acesso em: 13 fev. 2019.

GALIAZZI, M. C.; GONÇALVES, F. P. A natureza pedagógica da experimentação: uma pesquisa na licenciatura em química. Química Nova, São Paulo, v. 27, n. 2, p. 326-331, 2004. Disponivel em: http://dx.doi. org/10.1590/S0100-40422004000200027. Acesso em: 13 fev. 2019 .

GONÇALVES, F. P. A problematização das atividades experimentais no desenvolvimento profissional e na docência dos formadores de professores de Química. Tese (Doutorado) - UFSC, Florianópolis, 2009. Disponivel em: https://repositorio.ufsc.br/handle/123456789/92977. Acesso em: 15 dez. 2017.

GONÇALVES F. P.; MARQUES C. A. A problematização das atividades experimentais na educação superior em química: uma pesquisa com produções textuais docentes. Quimica Nova, São Paulo, v. 34. n. 5, p. 899-904, 2011. Disponivel em: http://dx.doi. org/10.1590/S0100-40422011000500030. Acesso em: 15 dez. 2017

LIMA, J. O. G. Perspectivas de novas metodologias no Ensino de Química. Revista Espaço Acadêmico Maringá, n. 36, p. 95-101, set. 2012. Disponivel em: http://www.educadores.diaadia.pr.gov.br/arquivos/ File/setembro2013/quimica_artigos/perspect_novas_metod_ens_quim.pdf Acesso em: 15 dez. 2018.

MINAYO, M. C. S. Ciência, técnica e arte: o desafio da pesquisa social. In: MINAYO, M. C. S. (org.). Pesquisa social: teoria, método e criatividade. Petrópolis, RJ: Vozes, 2001. p. 9-29.

MORAES, R.; GALIAZZI, M. C. Análise Textual Discursiva. 2. ed. Ijuí: Editora UNIJUÍ. 2011.

MOREIRA, A. F.; PEDROSA, J.G.; PONTELO I. O conceito de atividade e suas possibilidades na interpretação de práticas educativas. Ensaio - Pesquisa em Educação em Ciências, Belo Horizonte, v. 13, n. 3. p. 13-29, set./dez. 2011. Disponivel em: http://dx.doi.org/10.1590/198321172011130302. Acesso em: 13 fev. 2019.

OLIVEIRA, J. R. S. Contribuições e abordagens das atividades experimentais no ensino de ciências: reunindo elementos para a prática docente. Acta Scientiae, Canoas, v. 12, n. 1, p. 139-153, jan./ jun. 2010. Disponivel em: http://www.periodicos.ulbra.br/index.php/acta/ article/view/31. Acesso em: 13 dez. 2017.

POZO, J. I.; CRESPO, M. A. G. A aprendizagem e o ensino de ciências: do conhecimento cotidiano ao conhecimento científico. 5. ed. Porto Alegre: Artmed, 2009.

ROSITO, B. A. O Ensino de Ciências e a experimentação. In: MORAES, Roque (org.). Construtivismo e Ensino de Ciências: reflexões epistemológicas e metodológicas. 2. ed. Porto Alegre: EDIPUCRS, 2003. p. 195-208.
SILVA, R. T. et al. Contextualização e experimentação: uma análise dos artigos publicados na seção "experimentação no ensino de química" da revista química nova na escola 2000-2008. Ensaio - Pesquisa em Educação em Ciências, Belo Horizonte, v. 11, n. 2, dez. 2009. Disponivel em: http://dx.doi.org/10.1590/198321172009110206. Acesso em: 13 fev. 2019

TARDIF, M. Saberes docentes e formação profissional. 17. ed. Petrópolis, RJ: Vozes, 2014.

\section{Lúcia Maria de Araujo Quevedo ${ }^{1}$}

Mestra em Educação em Ciências pela Universidade Federal do Rio Grande do Sul (UFRGS, Porto Alegre, RS, Brasil).

\section{Andréia Modrzejewski Zucolotto ${ }^{1}$}

Doutora em Educação pela Pontifícia Universidade Católica do Rio Grande do Sul (PUCRS, Porto Alegre, RS, Brasil). Professora em Instituto Federal de Educação, Ciência e Tecnologia do Rio Grande do Sul (IFRS) em Porto Alegre, RS, Brasil.

\section{Endereço para correspondência}

Lúcia Maria de Araujo Quevedo

Rua Ramiro Barcelos, 2600, Prédio Anexo, Sala 10

Santa Cecilia, 90035-003

Porto Alegre, RS, Brasil

Andréia Modrzejewski Zucolotto

Instituto Federal de Educação, Ciência e Tecnologia do Rio Grande do Sul

R. Cel. Vicente, 281, Sala 17

Centro Histórico, 90030-041

Porto Alegre, RS, Brasil 